le portiQue $\begin{array}{ll}\text { Le Portique } \\ \text { Revue de philosop }\end{array}$

23-24| 2009

Animalité

\title{
Le [parlement des philosophes]
}

\section{(2) OpenEdition}

1 Journals

Édition électronique

URL : http://journals.openedition.org/leportique/2423

DOI : 10.4000/leportique.2423

ISSN : $1777-5280$

Éditeur

Association "Les Amis du Portique"

Édition imprimée

Date de publication : 28 septembre 2009

ISSN : 1283-8594

Référence électronique

"Le [parlement des philosophes] », Le Portique [En ligne], 23-24 | 2009, mis en ligne le 28 avril 2010, consulté le 25 mars 2021. URL : http://journals.openedition.org/leportique/2423 ; DOI : https://doi.org/ 10.4000/leportique.2423

Ce document a été généré automatiquement le 25 mars 2021.

Tous droits réservés 


\section{Le [parlement des philosophes]}

1 Le [parlement des philosophes]continue à contribuer à faire vivre la philosophie dans la cité, à Strasbourg, même s'il doit parfois bousculer ou réorganiser son programme et ses projets...

2 Tandis que le présent numéro présente la plupart des contributions qui ont été proposées lors du colloque consacré à l'Animalité du 4 au 7 octobre 2007, l'année universitaire qui se termine a été l'occasion de plusieurs manifestations.

Du 9 au 11 octobre 2008, le Colloque «Les usages du vivant: quels enjeux pour les biotechnologies?» a mobilisé de nombreux participants venant de divers horizons. Ce colloque, ambitieux et riche, a été longuement évoqué par la dernière Chronique, dans le $\mathrm{n}^{\circ} 22$ du Portique.

4 En janvier 2009, du 8 au 10, ce sont trois journées qui ont été consacrées à Rozensweig, sous la direction de Dimitri Sandler et Petar Bojanic. Les responsables de ces journées ont privilégié quelques textes que Franz Rosenzweig, soldat autrichien combattant dans la défense anti-aérienne, a écrits au cours des dernières années de la Première Guerre mondiale sur le front des Balkans (en Macédoine et en Serbie). Car c'est l'expérience de la guerre et le départ d'Allemagne qui ont contraint l'auteur de Hegel et l'État (1920) et de L'Étoile de la Rédemption (1921) à penser la transformation de l'ère européenne en une ère planétaire et à expliquer le "passage » de la terre au monde et la rivalité entre les peuples. Il s'agissait, à partir de ces textes, de montrer dans quelle mesure Rosenzweig est le précurseur et le chef de file de la pensée de l'espace européen et, en général, du processus de globalisation.

Dès l'automne 2009, une journée préparée par Andrea Potestà, Aïcha Liviana Messina et Alexis Zimmer (organisée en collaboration avec le Collège international de philosophie et l'Université de Strasbourg) sera consacrée, le 2 octobre, à «L'éthique du refus ». Elle sera l'occasion, à travers la rencontre avec différentes associations militantes, de prêter attention aux enjeux, aux possibilités effectives et aux difficultés du militantisme. La notion de «refus » décrit le devoir inconditionnel de franchir une limite, de sortir du retrait de l'« intellectuel » pour prendre position dans l'espace public : une éthique ou une politique du refus nomme ainsi, non pas des règles d'actions à observer - qui nous maintiendraient dans les limites d'une morale - mais l'épreuve d'une sortie, d'une 
parole et d'une existence entièrement tournées vers l'extériorité, face à ce qui fait figure d'intolérable.

Quant au Colloque Lacoue-Labarthe, organisé par Jacob Rogozinski, il aura lieu du 22 au 24 octobre. C'est un temps fort de l'activité du [parlement des philosophes]: les membres fondateurs du Parlement ont à cœur de dire leur admiration, voire leur dette, à ce penseur qui a enseigné pendant 30 ans à l'Université de Strasbourg, qui a présidé, à un moment critique de son histoire, le Collège international de Philosophie et qui a suivi attentivement les activités du Parlement. Avec le soutien de l'Université de Strasbourg, ce colloque entend souligner aussi bien l'envergure de sa pensée, étrangère à toute " pose ", que la diversité des objets auxquels il a consacré une réflexion toujours libre et novatrice. C'est donc en travaillant sa pensée, en la discutant et en la remettant en jeu que les organisateurs de ce colloque international, ouvert à des chercheurs et à des étudiants venus de tous les pays, se proposent de lui rendre hommage, en faisant alterner conférences, tables rondes et lectures de textes poétiques

7 Le 30 novembre 2009, dans le cadre des Rencontres Strasbourg-Méditerranée qui, un an sur deux, alternent avec le Festival Strasbourg/Méditerrenanée, Jacob Rogozinski prendra part à une table ronde organisée à la Librairie Kléber. Le thème des rencontres étant celui des Héritages, cette table ronde est consacrée à " L'héritage des Grecs ».

8 Plus tard, dans l'année, en mars 2010, un autre colloque international est prévu, consacré au sujet « Mystique et philosophie ».

9 Ce colloque s'attachera principalement à la question de la naissance de la mystique dans sa confrontation avec le courant dit rationaliste, à la question de l'écriture mystique - comment transcrire ou décrire l'expérience extatique ? - et à celle de l'excès, du passage à la limite que la mystique, au sens large, semble produire sur le mode habituel de notre rationalité. Comment le discours philosophique peut-il rendre compte de l'expérience mystique sans pour autant la ramener à un déjà-su, sans désactiver son sens subversif? Comment penser la tension entre amour mystique et rationalité philosophique : ne peut-on penser une modification de la rationalité ellemême, ou tout au moins de son mode opératoire, par son appréhension de la mystique qui la pousserait à la limite de ses forces? Telles sont les questions qui seront abordées au cours de trois journées.

10 Pour toute information ou précision sur ces activités, les dates, les lieux, ainsi que pour adhérer ou consulter les archives déjà réunies, rendez-vous sur le site :

http ://www.parlement-des-philosophes.org ou contactez :

postmaster@parlement-des-philosophes.org 